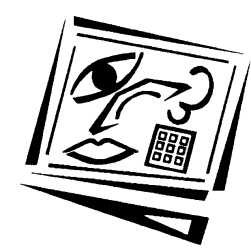

\title{
Interaction online: Above and beyond requirements of assessment
}

\author{
Meg O’Reilly and Diane Newton \\ Southern Cross University
}

\begin{abstract}
Today's literature is filled with new paradigms for learning, specifically in relation to the increasing adoption of computer mediated techniques for interactive learning. In many cases, learning may now be enhanced through the experience of a shared online environment for critical discussion, knowledge building and the establishment of supportive social communities. Research data obtained from social science students at Southern Cross University over two semesters reveals students' perceptions of the importance of online discussion whether these are assessable or not. This paper presents some findings and explores the impact of the emergence of a student-centred social learning environment.
\end{abstract}

\section{Introduction}

A great deal has now been written which confirms that assessment is the key to learning in traditional settings (Ramsden, 1992), termed the de facto curriculum in distance education contexts (Rowntree, 1977) and the driver of students' approaches to study (Morgan, 1993). In all forms of distance education today - print based, mediated via video or tele-conference, or supplemented by computer based communications, assessment tasks can be seen as the active components of study. Assignments provide learners with opportunities to discover whether or not they understand, if they are able to perform competently and demonstrate what they have learnt in their studies. Furthermore, the feedback and grades which assessors communicate to students serve to both teach and motivate (Thorpe, 1998).

In such a paradigm of learning through assessment, new innovations in teaching and learning are likely to be incorporated within the assessment scheme in order to be 'road-tested' through engagement by a critical mass of learners. We have seen this situation occurring within the online learning environment in higher education, where teachers are making various forms of online discussion mandatory in order to ensure some level of activity. In what is known as 'third generation distance education' 
(Nipper, 1989), it can be said that the online learning environment has extended the range of skills to be assessed, for example, collaboration between remote students, information literacy skills and web design. Furthermore, opportunities to explore new assessment methods and styles are now afforded, for example, ICQs, timed online exams, group projects, international collaboration, peer and self assessment ( $\mathrm{O}^{\prime}$ Reilly \& Morgan, 1999). All these developments serve to blur the distinctions between on campus and off campus learning while strengthening the notion that students wherever they are, work primarily for grades.

Without attempting to debunk the clearly supported notion that assessment is critical to learning, this paper explores recent evidence from online teaching and learning experiences which indicates that online communication among learners has other intrinsic spin-offs. This paper will discuss the social experiences in construction of knowledge as well as the emergence of both social and knowledge communities online.

\section{Motivators for discussion}

Recent discussions on the eModerators List (Berge \& Collins, 2001) have debated whether giving credit is indeed the only way to ensure students engage in web based discussion forums. To the question "Do they need marks to participate?" (Malcolm 2001), twenty-four answers were posted. Each respondent, confirmed the necessity to assess students in order to achieve "engagement" and "participation". One participant of the list (Hart, 2001) states:

People I find are BUSY - everyone I know uses ALL of their 24 hours per day. Every bit of time spent on a discussion board could be spent otherwise. If there is no credit for doing so, it is rational to spend time doing things that count more [emphasis in original].

This is reminiscent of the work by Lockwood (1992) who investigated the costs and benefits for open and distance learners when it came to optional learning activities in print based study packages. Lockwood's findings were much the same as those reflected in the above comment that students weigh up what they can afford in terms of 'course focus', 'self focus' or 'assignment focus'. Time and attention to study are allocated in the most pragmatic ways in order to satisfy both intrinsic and extrinsic requirements.

Now that many of the students in our programs have had previous experiences of online participation, we wonder about the decisions they are making in terms of benefits of online discussion irrespective of whether or not they are being assessed. At this time there is a range of assessment options being implemented in the School of Social \& Workplace 
Development (SaWD) at Southern Cross University, including units with no compulsory graded online assessment tasks, or one compulsory online task plus encouragement for online participation, or compulsory graded weekly online activities. The surveys we conducted reveal something of the students' attitudes to the social and communal aspects of being within an online group in these units.

\section{Collaborative evaluation research}

After three years of design, development and delivery of web based teaching in a wide range of approaches, SaWD academic staff have gained significant expertise in pedagogically sound course design. In addition to ongoing collaboration with educational design staff from the Teaching and Learning Centre (TLC) on approaches to teaching, learning and assessment online, SaWD staff have recently begun a series of evaluation projects to further inform their teaching practices. This paper reports some of the latest findings from surveys conducted by SaWD with input from TLC in respect of discussion and interaction occurring online.

\section{Action learning methodology}

The ongoing and iterative nature of course design comfortably lends itself to a cyclic and developmental approach to research and development as facilitated by action learning methods (Dick, 1997). To ensure that online units are responsive to learners' needs and that staff development benefits are maximised, SaWD staff with some input from TLC, collectively embarked upon a series of action learning cycles to capture the essence of their teaching and professional development experiences first hand.

Though initially focusing on an action research staff development model for online design (Ellis \& Phelps, 2000), most recently the focus for action learning has included an investigation of the students' responses to the online learning experience. There is a need to understand the way students are using the online medium and the processes that are enhancing their learning. In 1995, Bates (p.202) clearly stated:

\footnotetext{
It is still open to debate whether this technology [computer-mediated communication] will result in truly new paradigms, or merely allow valued old paradigms to be used more effectively for learners at a distance.
}

The purpose of obtaining student feedback from SaWD students was therefore not so much to search for proof of the School's achievements in integrating computer mediated communications into its programs, but to gain information which would help to initiate and continue improvements in interactive online teaching and learning. We sought to investigate whether students' online communications were telling us more about a 
peer based social context for learning than we might have assumed, given the extensive literature on importance of assessment and tutor feedback (Thorpe, 1998).

Two online surveys were conducted with students - late in semester 2, 2000 and early in semester 1,2001. The aim of these surveys was to gather feedback from students on their perceptions of features that were aiding or distracting from their learning in the online environment, more specifically the relevance of online discussion features for learning.

Timely analysis of the data from the first survey has allowed immediate fine tuning of unit design and the implementation of student support mechanisms (Newton \& Ledgerwood, 2001) as well as enabling a responsive approach by teaching staff to improve their pedagogical strategies. The latter activities have particularly occurred in relation to the design and expectations of students' communication skills, levels and purpose of interaction. Subsequent cycles of information collection, reflection and implementation of change are continuing.

What are students communicating?

'Collaborative learning' is discussed in the literature as a process that involves interdependence and the progress towards shared goals (Palloff \& Pratt, 1999). In this context we see the emergence of the concept of a learning community (Hill, 2001). These terms are useful in the general discussion of online communication as they focus more on the processes and purposes of online communication for students rather than just on the online medium that allows interaction to occur.

The terms 'interaction' and 'communication' have been used a little interchangeably in this paper. However, distinctions are made within the literature. In the broad sense of the word 'interaction' can be defined as including:

- learners' interaction with content in terms of the level of their critical thinking and critical reasoning skills and,

- learners' interaction with others in terms of negotiation of meaning and co-construction of knowledge in shared learning environments (Sringam \& Greer, 2000, pp.82-3).

The evaluation research reported here was particularly aimed at examining the interactive communication among students rather than viewing it as a one way transfer of information. Educational design staff in the TLC were keen to discover outcomes from the designs for online interaction which have been used by SaWD over the past two semesters in order to defuse the kind of sentiment expressed by Villalba and Romiszowski (2000, p.1111): 
It is a sobering thought that in all the centuries since the Gutemberg [sic] print technology facilitated the mass dissemination of text, we are still struggling with the issues of mediocre textbooks, instructional manuals that fail to instruct and communications (including on-line texts and hypertexts) that just do not communicate.

If, as we have observed, students are becoming more experienced in this learning environment, then the challenges and demands on staff need to also continue to adapt. New forms of social interaction afforded in the online context require new responses by teachers and learners alike. As Sims (1999, p.309) highlights, it is important to include:

...learner representatives in the design process, as they are a group who can verify the effectiveness of the interactive experience in terms of participation, engagement and learning outcomes.

\section{Results}

First survey (Semester 2, 2000)

29 students of 49 enrolled in SaWD online units replied to the survey conducted in Semester 2, 2000 - 60\% response rate. $72 \%$ indicated they were mature aged (over 25), 76\% female. Overall 62\% had no previous experience of online modes of study.

\section{Second survey (Semester 1, 2001)}

The second survey was made available to all students with access to SaWD online units. The potential respondents in this survey included students enrolled online, or externally with online access, or internally enrolled students with online access. Such a diverse cohort reflects the move towards a mixed mode of delivery at Southern Cross University as lecturers explore relative advantages of the online medium to support learning. 61 students over 14 SaWD units delivered online replied to the second survey representing a response rate of about $10 \%$ of all students who accessed a SaWD online unit by the end of Semester 2.

The response rate for students relying solely on the online medium for learning would have been higher than $10 \%$ as the total possible respondents counted included all students who accessed an online unit, even only once, by the end of the Semester and who did not rely on unit online delivery. The administration system did not allow us to identify the total number of students who were enrolled in the mixed modes. Despite this low rate of return, the trends reported confirmed the findings of the first and the more detailed qualitative answers and supported trends revealed in the first survey, particularly the value of peer-peer interaction. These results also provide feedback for further survey questions. 
Similarly to Survey 1 the students were predominantly mature aged (83\%), mostly female $(73 \%)$, studying from homes outside metropolitan areas $(67 \%)$, mostly inexperienced in online mode of learning $(79 \%)$.

Overall the respondents enjoyed their unit with none reporting that they "Did not enjoy (the Unit) at all" and 48\% (Survey 1) and 55\% (Survey 2) reporting that they enjoyed the unit a "Great" or "Very Great" amount. Respondents expressed a high level of satisfaction with the online delivery mode with a preference for online delivery mode for the unit $(79 \%$, Survey 1) rather than a paper based off campus delivery. Only 7\% (Survey 1) and $5 \%$ (Survey 2) reported that they would not take a further online unit. Table 1 shows students are reporting more competence in the use of online discussion tools.

Table 1: Percentage of students reporting an 'Average' or higher competence with online tools

\begin{tabular}{|l|c|c|c|c|}
\hline $\begin{array}{l}\text { Reported competent } \\
\text { with: }\end{array}$ & Survey 1 & No. students & Survey 2 & No. students \\
\hline Word processing & $100 \%$ & 49 & $97 \%$ & 59 \\
\hline Email & $97 \%$ & 48 & $90 \%$ & 55 \\
\hline Internet browsers & $94 \%$ & 46 & $89 \%$ & 54 \\
\hline Asynchronous discussion & $45 \%$ & 22 & $70 \%$ & 43 \\
\hline Synchronous chat & $28 \%$ & 14 & $47 \%$ & 29 \\
\hline
\end{tabular}

\section{Interaction}

One of the most striking findings in both these surveys was the emphasis placed by students on peer to peer interaction. In the first survey, $82 \%$ students valued peer to peer interaction highly for learning, while 55\% highly valued interaction with staff. Similarly, in the second survey 58\% valued peer to peer interaction most highly for learning and $21 \%$ valued interaction with staff most highly.

Details of interaction

Following the work of Sringam and Greer (2000), our second survey (2001) sought to ask students to make some distinctions between their activities within discussion forums at an individual level and their interactions in terms of working with other students. This "work" was not restricted to assessable tasks (see Table 2).

In terms of working with others, we asked students to give an indication of the specific nature of their interactions according to the selections provided as extracts from the Cognitive Development and Interactive Analysis Model (Sringam \& Greer, 2000, p.86) (see Table 3). 
Table 2: Individual activities in the discussion forums

\begin{tabular}{|l|c|}
\hline \multicolumn{2}{|c|}{ Discussion forums - Individual use } \\
\hline Haven't used & $2.7 \%$ \\
\hline Read the postings & $27.7 \%$ \\
\hline Replied to a posting & $28.7 \%$ \\
\hline New thread - started a new idea & $18.1 \%$ \\
\hline New thread - asked a question & $10.1 \%$ \\
\hline Activities for assignment & $12.8 \%$ \\
\hline
\end{tabular}

Table 3: Working with others in discussion forums

\begin{tabular}{|l|c|}
\hline \multicolumn{2}{|l|}{ Discussion Forums - Working with other students } \\
\hline Haven't worked with others & $33.7 \%$ \\
\hline Planning, organising & $6.3 \%$ \\
\hline Encouraging others & $16.8 \%$ \\
\hline Identifying disagreement & $9.5 \%$ \\
\hline Clarifying meaning & $16.8 \%$ \\
\hline Helping understanding & $8.4 \%$ \\
\hline Summarising agreement & $8.4 \%$ \\
\hline
\end{tabular}

How students value interaction

Overall there was very positive response to interaction in terms of social support and unit focused learning support. The importance of social interaction was evident, in particular in forming friendships, offering advice, empathy and encouragement to continue studying in this new learning environment. Students who had previously studied via traditional paper based distance education commented on the value of interaction for overcoming isolation and engaging in mutual support with peers. It was evident in Survey 2 that some students are becoming experienced online students and are developing expectations of a good online learning environment especially in their expectations for discussion and interaction with peers and lecturers. A sample of student comments from both surveys follow (with some students being concurrently enrolled in more than one subject).

Overcoming a sense of isolation was important for students' studying externally. In Survey 2 some students studying externally with some online access expressed the value of the online interaction for learning and a desire for studying online units in the future. A sense of becoming a part of a group was valued for learning: 
- I have been an external student for the past four years. Even though I have attained pretty good grades learning on my own. I must admit that I really like on-line experience. It opens up new lines of thought and I can see some progress as I go.

- I wish I'd had it when I started 2 years ago. The discussion and chance to interact with other students is essential to know I am on the right track, and to get support and help.

Specific comments on the value of interaction:

- We have formed a group to complete an assignment so we have had a fair bit of group interactivity.

- I think we interact wonderfully well and certainly online friendships are building.

- Excellent - everyone seems to use the online connection to work together and there is increased level of support.

- The experience has kept me motivated to continue and to get support from other students when I've come across difficult concepts in readings and study guides.

Their ideal learning situation includes support from online discussion:

- I appreciate the flexibility of the online unit and I feel that you actually get to know your lecturer better than if you were actually attending.

- The combination of paper study material and access to online contact with students and lecturers.

Respondents enjoyed the interaction with others as personal support when they experienced trouble with motivation or other personal problems:

- When I considered dropping out... my team encouraged me to take time out and they supported me through the worst part of my emotional turmoil. I learnt that the trust in our group is a very real part of us doing well.

Negative comments about interaction Respondents disliked learning when there was less interaction with other students than they expected and when the instructions for use of the discussion forum or unit objectives were not clear. Feedback on the assessment tasks also suggests that too much compulsory discussion that is not structured or moderated is not liked by students. Compulsory online weekly assessed tasks were considered:

- Too much to do specifically each week.

- Too many comments to read and take in. 
Some respondents initially felt uncomfortable with the technology, but found that the lecturers or other students could usually provide assistance in the first few weeks:

- I enjoyed the availability of the tips of other students regarding online tools.

Implementation responses to surveys

In response to the outcomes of both surveys, additions were made within the SaWD online learning environment by creating a Student Centre where additional help files were located to provide a central support resource area, and general unstructured support was encouraged among students. Subsequently, additional instructions were provided about using the discussion forums and downloading software required for some of the online features, such as Adobe Acrobat, and Flash (Newton \& Ledgerwood, 2001).

Feelings of frustration and low confidence were more evident in the beginning of the Semester in Survey 2 with students new to online learning having initial difficulty in using discussion forums and navigating around the units. However, there was evidence in the un-moderated Student Centre forums that students were overcoming these problems and assisting each other's progress, after a few weeks into the unit. Further induction instructions and a demonstration resource are planned in order to provide students with support to feel more capable and confident in the online environment.

\section{Discussion}

\section{Mutual support via online communication}

Establishing a safe environment for learning through a perception of open communication where mutual and democratic support can be experienced, is one of the keys suggested in the building of communities online (Hill, 2001). Clearly the comments from students show that social interaction is considered an important element of being online, both to support learning and for mutual support of learners.

Laurillard's (1993) explanation of the importance of learning through a conversational framework can be reiterated from the results of this survey. However in addition, the results provided here by the social science students go towards emphasising the importance of peer to peer interaction for learning and not just the conversational framework occurring between student and teacher. 


\section{Disciplinary relevance of discussion}

Evidence might further be sought on the importance of disciplinary practices and their effects upon students' level of participation in discussion online. Recent comments from educational design staff (Morgan, pers. comm. 13 June 2001) illustrate that in the area of humanities, where discursive approaches to learning are pivotal, previous practices of structuring assessable discussions have now ceased, due to the high uptake of student interaction in the online context. The level of active interaction in courses such as the humanities area and the social science area which we researched, can thus be related to both the relevance of the discipline as well as students becoming more experienced with using discussion as part of their learning activities.

\section{Social cohesion}

Another key to consider is that of the social cohesion of the group assisting in the process of learning (Brandon \& Hollingshead, 1999). Not only need the learners develop technical and social skills for the online environment, but also our students in Survey 2 were telling us of the online social context which they considered to improve their learning experience. However, the lack of traditional social elements such as physical appearances, tone of voice, linguistic habits, accents or impediments, have meant to these students that their formation of a network is based around mutual valuing of learning goals, without other distractions (Parry \& Dunn, 2000).

The expression of shared goals (Thorpe, 1998; Palloff \& Pratt, 2000; Hill, 2001) can be seen in the students' reports of encouraging others (as opposed to competing with each other), helping understanding and summarising agreement.

\section{Social constructivism}

Social construction of knowledge has been discussed in many ways since Vygotsky's work on the effects of encountering the zone of proximal development through cooperative learning (in Doolittle, 1997), Piaget's theory of learning through multiple perspectives (in London, 1988), and cognitive-elaboration theory (Brandon \& Hollingshead, 1999). These theories all provide clear support for the positive experience being reported by our social science students regarding the value of online interaction.

Research by Jiang and Ting (2000) showed that students felt their learning was enhanced when online discussion was a key feature of the course. What was interesting with our survey of social science students was that 
the students were initiating the social interaction themselves and seeing this as supporting their learning.

\section{Benchmarking}

Comments from students reflecting on their personal approaches to learning and up-skilling with the technologies, such as, 'We were all feeling the same anxiety about meeting deadlines and subject and assignment material', provide evidence of the importance of communication for the purpose of benchmarking. In particular, in groups of students who are remote from each other, this benchmarking facility is highly important, 'fostering deep or meaning approaches to learning in online settings' (Parry \& Dunn, 2000, p.227).

\section{Motivation, confidence and making new friends}

Harasim (1993) speaks most positively of the networked environment:

As a technological innovation and a social construct, global networks impact the ways in which we communicate, with transformative implications for how we form community, how we work, and how we learn (p.16).

Potentials described by Harasim (1993) for interaction on a vast range of subjects with both peers and experts from around the world are now clearly being realised, with the process of 'knowledge building' and 'information sharing' being seen as actively impacting upon most spheres of society. Note the number of online forums now available for following up on the guest speakers of TV and radio presentations.

Intrinsic motivation for engaging in online discussion is also evident from our social science students, many of whom stated the importance of gaining confidence in a safe (ie. non-assessed) context, forming friendships online, and spontaneously offering suggestions and hints for handling what was for some a most unfamiliar environment. The idea of making new friends through online discussion has also been referred to in recent research by Baskin (in press) using Kirkpatrick's model to explore the effectiveness of collaborative online group work in the context of business studies.

\section{Networked intelligence}

In his keynote address at the AusWeb01 Conference, Walter Stewart (2001) concluded his presentation with the message that the future of learning is not about networks, computers, courses, degrees and institutions... it's about networked intelligence. Phil Agre (2001), another keynote speaker of 
the conference talked of the wired university as an environment that promulgated social networks in a culture where knowledge is accepted as community property.

\section{Conclusion}

In conclusion, the surveys have helped confirm that the online social networks and online knowledge communities described by Stewart and Agre are an extension of our lives offline. Online students are taking advantage of the opportunities to interact, to form social networks that are contributing to a learning network. Gaining confidence and a sense of freedom in an unfamiliar learning environment is important for communication to develop. These social groups may be based on the enrolment in a unit and the need to achieve assessment tasks, but sharing understanding and supporting each other in an open unstructured forum suggests that deeper social and learning communication networks are developing among learners. In the online context we can expect that students will increasingly see the benefits to themselves of staying in touch with others and shaping their own understanding. In addition, it has been inspiring to see that Jacobson's (1993) hopes for humanising the online environment are gradually coming to fruition, as learners demonstrate civility, conviviality, reciprocity, harmony, edification, artfulness and spirituality, above and beyond the requirements of their assignments.

\section{References}

Agre, P. (2001). How can the Web support intellectual life in a democratic society? Keynote presentation at AusWeb01 Conference, Coffs Harbour, NSW.

Baskin (2001). Using Kirkpatrick's Four-Level-Evaluation Model to explore the effectiveness of collaborative on-line group work. In G. Kennedy, M. Keppell, C. McNaught \& T. Petrovic (Eds.), Meeting at the Crossroads. Proceedings of the 18th Annual Conference of the Australian Society for Computers in Learning in Tertiary Education. (pp. 37-44). Melbourne: Biomedical Multimedia Unit, The University of Melbourne. [verified 6 Apr 2001]

http: / / www.medfac.unimelb.edu.au / Ascilite2001 / pdf/ papers/baskinc.pdf

Bates, A. (1995). Technology, Open Learning and Distance Education. London: Routledge.

Berge, Z. \& Collins, M. (2001). eModerators list. http:/ / www.eModerators.com/

Brandon, D. \& Hollingshead, A. (1999). Collaborative learning and computersupported groups. Communication Education, 48(2), 109-126.

Dick, B. (1997). Action Learning and Action Research. [verified 6 Apr 2002] http: / / www.scu.edu.au/schools/gcm/ar/arp/actlearn.html 
Doolittle, P. (1997). Vygotsky's Zone of Proximal Development as a Theoretical Foundation for Cooperative Learning. Journal on Excellence in College Teaching, 8(1), 83-103.

Ellis, A. \& Phelps, R. (2000). Staff development for online delivery: A collaborative, team-based action learning model. Australian Journal of Educational Technology, 16(1), 27-44. http: / / ascilite.org.au/ajet/ ajet16/ellis.html

Harasim, L. (Ed). (1993). Global Networks: Computers and International Communication. MIT Press.

Hart, D. (2001). “Do they need marks to participate?" Response to thread in emoderators discussion list, 19 June 2001. Zane Berge \& Mauri Collins (Moderators). http:/ / www.eModerators.com/

Hill, J. (2001). Building community in Web-based learning environments: Strategies and techniques. In A. Treloar \& A. Ellis (Eds), AusWeb01: The Seventh Australian World Wide Web Conference, Coffs Harbour: Southern Cross University Press, 157-169. [verified 6 Apr 2002] http: / / ausweb.scu.edu.au/aw01/ papers/ refereed/hill/

Jacobson, (1993). Sailing through Cyberspace: Counting the stars in passing. In L. Harasim (Ed), Global Networks: Computers and International Communication. MIT Press, 327-341.

Jiang, \& Ting (2000). A study of factors influencing students' perceived learning in a Web-based course environment. International Journal of Educational Telecommunications, 6(4), 317-338.

Laurillard, D. (1993). Rethinking University Teaching. London: Routledge.

Lockwood, F. (1992). Activities in Self-Instructional Texts. London: Kogan Page.

London, C. (1988). A Piagetian constructivist perspective on curriculum development. Reading Improvement, 27, 82-95.

Malcolm, P. (2001). “Do they need marks to participate?" Start of thread in emoderators discussion list, 19 June 2001. Zane Berge \& Mauri Collins (Moderators). http:/ / www.eModerators.com/

Morgan, A. (1993). Improving Your Students' Learning: Reflections on the Experience of Study. London: Kogan Page.

Newton, D. \& Ledgerwood, T. (2001). Evolving support for online learning: An action research model. Moving Online II Conference Proceedings, Lismore, NSW, Southern Cross University. [verified 6 Apr 2002]

http:/ / www.scu.edu.au/schools/sawd/moconf/papers2001/newton_ledgerwood.pdf

Nipper, S. (1989). Third generation distance learning and computer conferencing. In R. Mason \& A. Kaye (Eds), Mindweave: Communication, Computers and Distance Education, Oxford: Pergamon Press, 63-73. [verified 6 Apr 2002] http: / / icdl.open.ac.uk/literaturestore/mindweave/chap5.html 
O'Reilly, M. \& Morgan, C. (1999). Online assessment: Creating communities and opportunities. In S. Brown, P. Race \& J. Bull (Eds), Computer Assisted Assessment in Higher Education. London: Kogan Page SEDA, 149-161

Palloff, R.M. \& Pratt, K. (1999). Building Learning Communities in Cyberspace: Effective Strategies for the Online Classroom. San Francisco: Jossey-Bass.

Parry, S. \& Dunn, L. (2000). Benchmarking as a meaning approach to learning in online settings. Studies in Continuing Education, 22(2), 219-234.

Ramsden, P. (1992). Learning to Teach in Higher Education. London: Routledge.

Rowntree, D. (1977). Assessing Students: How shall we know them? London: Kogan Page.

Sims, R. (1999). The interactive conundrum I: Interactive constructs and learning theory. In J. Winn (Ed), Responding to Diversity. Proceedings of 16th Annual conference of ASCILITE. Brisbane: QUT Teaching and Learning Support Services. [verified 6 Apr 2002]

http: / / www.ascilite.org.au/conferences / brisbane99/ papers/ sims.pdf

Sringam, C. \& Greer, R. (2000). An investigation of an instrument for analysis of student-led electronic discussions. In R. Sims, M. O’Reilly \& S. Sawkins (Eds), Learning to Choose - Choosing to Learn. Proceedings of 17th Annual ASCILITE Conference, Coffs Harbour: Southern Cross University Press, 81-91. [verified 6 Apr 2002]

http: / / www.ascilite.org.au / conferences / coffs00 / papers / chinawong_sringam.pdf

Stewart, W. (2001). "What is learning when understanding is visual?" Keynote presentation at AusWeb01 Conference, Coffs Harbour, NSW.

Thorpe, M. (1998). Assessment and 'third generation' distance education. Distance Education, 19(2), 265-286.

Villalba, C. \& Romiszowski, A. (2000). Structural communication and Web based instruction. In J. Bourdeau \& R. Heller (Eds), Proceedings of EdMedia 2000, Montreal, Canada: Association for the Advancement of Computing in Education, 1111-1116.

Meg O'Reilly, Teaching and Learning Centre, Southern Cross University, Australia.oreilly@scu.edu.au

Diane Newton, School of Social \& Workplace Development, Southern Cross University, Australia.dnewton@scu.edu.au

An earlier version of this article was published under:

O'Reilly, M. \& Newton, D. (2001). Interaction online: Above and beyond requirements of assessment. In G. Kennedy, M. Keppell, C. McNaught \& T. Petrovic (Eds.), Meeting at the Crossroads. Proceedings of the 18th Annual Conference of the Australasian Society for Computers in Learning in Tertiary Education. (pp. 461-470). Melbourne: Biomedical Multimedia Unit, The University of Melbourne.

http:/ / www.medfac.unimelb.edu.au/Ascilite2001/pdf/ papers/oreillym.pdf 